\title{
EL SISTEMA ELECTORAL DE LAS CORTES GENERALES A TRAVÉS DE SU PROCESO DE CONSTITUCIONALIZACIÓN
}

\author{
SILVIA SORIANO MORENO \\ Profesora de Derecho Constitucional \\ Universidad de Extremadura
}

TRC, núm. 45, 2020, pp. 567-596

ISSN 1139-5583

\begin{abstract}
SUMARIO
I. Introducción. II. Antecedentes al sistema electoral constitucional: la Ley para la Reforma Política. III. Los debates constitucionales en el Congreso. VI. Los debates constitucionales en el Senado. V. Conclusiones.
\end{abstract}

\section{INTRODUCCIÓN}

El sistema electoral español, especialmente en lo referente al Congreso de los Diputados, ha sido objeto de numerosos estudios referidos a sus logros, carencias y problemas de proporcionalidad. Cuando realizamos un acercamiento a la cuestión, resulta de especial interés el análisis de cómo el sistema electoral se creó en su momento, mediante el establecimiento de las bases de lo que han venido siendo sus elementos y que han dado lugar a las diversas configuraciones parlamentarias y, por consiguiente, de Gobierno. Estos resultados electorales han sido estudiados en muchas ocasiones, llegándose a la conclusión de que los elementos configuradores del sistema dan lugar a un sesgo mayoritario y conservador, debido a la configuración de las circunscripciones más pequeñas ${ }^{1}$. A

1 En este sentido, Lago, I. y Montero, J.R., «'Todavía no sé quiénes, pero ganaremos’: manipulación política del sistema electoral español», Zona Abierta, 110/111, 2005, p. 282, donde se realiza un análisis de los procesos electorales desde 1977 hasta 2004. Sobre las Elecciones Generales de 2016 hemos tratado en Soriano Moreno, S., «El sistema electoral del Congreso de los Diputados: análisis, proporcionalidad y propuestas de mejora», en Palacios Romeo, F.J. y Cebrián Zazurca, E., Elegir cómo elegir: retos y urgencias del régimen electoral en España, Fundación Manuel Giménez Abad, Zaragoza, 2018, pp. 73-128. 
modo introductorio, resulta conveniente recordar brevemente estos elementos que componen el sistema electoral actual a las Cortes Generales y en qué preceptos se han sido concretados. El actual sistema electoral del Congreso de los Diputados obedece a los elementos que han venido operando prácticamente en su totalidad desde antes de la aprobación de la Constitución Española de 1978.

Debemos partir de la configuración constitucional, recogida en el artículo 68 de la Constitución Española (en adelante, CE). Así, se establece que el Congreso se compone de un mínimo de 300 y un máximo de 400 escaños, determinando para su elección el sufragio universal, libre, igual, directo y secreto. Además, que la circunscripción electoral será la provincia, asignando una representación mínima inicial a cada circunscripción y distribuyendo los demás en proporción a la población, salvo en el caso de Ceuta y Melilla que estarán representadas cada una de ellas por un escaño. Finalmente, exige la Constitución la atención a criterios de representación proporcional. Todo este marco recoge, básicamente, los mismos criterios ya determinados por la Ley 1/1977, de 4 de enero, para la Reforma Política (en adelante LRP) y aprobados por las Cortes franquistas en 1976.

Sobre esta base constitucional del art. 68 CE, ha sido la Ley Orgánica 5/1985, de 19 de junio, del Régimen Electoral General (en adelante, LOREG) la que ha venido a concretar los elementos del sistema. Sin embargo, estos elementos vienen a repetir prácticamente los escogidos por el Gobierno para el Real Decreto-ley 20/1977, de 18 de marzo, sobre Normas Electorales (en adelante RDLNE), que determinó los criterios para las elecciones de junio de ese año.

El número de escaños del Congreso de los Diputados se establece en el art. 162.1 LOREG que —como ya lo hiciera la Disposición Transitoria Primera de la LRP — fija en 350 el número de escaños a repartir. El art. 162.2 de la LOREG fija por su parte el mínimo constitucional exigido para cada circunscripción en dos escaños — sin olvidar el único asignado a Ceuta y a Melilla—. El apartado tercero de este artículo instituye el sistema de reparto de los 248 escaños restantes atendiendo a la población de cada circunscripción. Es de destacar que las cifras determinadas por este artículo para este reparto de escaños hacen referencia a la población total de las circunscripciones, no al censo electoral efectivo, lo cual también es una opción del legislador a tener en cuenta, ya que cuanto mayor es la población de la circunscripción, mayor resulta el déficit de representación ${ }^{2}$. Esta concreción de dos escaños asignados como representación mínima inicial para cada circunscripción — salvo Ceuta y Melilla - recoge también la previsión determinada por el RDLNE que aclaraba en el apartado IV de su Preámbulo que «se ha considerado conveniente asegurar un número inicial

2 Penadés, A. y Santiuste, S., «La desigualdad en el sistema electoral español y el premio a la localización del voto», Revista Española de Ciencia Política, n 32, julio 2013, p. 93. 
de dos Diputados por provincia y dividir el resto de los Diputados en función de la población».

El art. 163 de la LOREG explica las reglas de asignación de escaños según la fórmula D'Hondt y la barrera electoral del 3\%, siendo este artículo prácticamente idéntico al art. 20 del RDLNE que ya justificaba en el apartado IV de su Preámbulo su elección por cuanto «supone un poderoso corrector del excesivo fraccionamiento de las representaciones parlamentarias. A esta misma finalidad, responde la exclusión en la atribución de escaños de aquellas listas de candidatos que no bubieran obtenido, al menos, el tres por ciento de los votos emitidos en la circunscripción».

Finalmente, los arts. 169 y 172 de la LOREG establecen que las listas de las candidaturas serán por el sistema denominado de listas cerradas y bloqueadas, tal y como también hizo el art. 20 del RDLNE. Aunque este elemento no tiene un impacto directo en la proporcionalidad o no del sistema desde el punto de vista cuantitativo, sí es importante mencionarlo, por los efectos que genera para la legitimidad del procedimiento electoral, la democracia interna de los partidos, la realidad del mandato imperativo y la responsabilidad de los cargos electos ${ }^{3}$. En relación con esto, cabe destacar también una más reciente modificación introducida en el sistema de listas a través de la Ley Orgánica 3/2007, de 22 de marzo, para la igualdad efectiva de mujeres y hombres, que incorpora el art. 44bis de la LOREG, mediante la cual se establece la necesidad de presencia equilibrada entre mujeres y hombres en las listas. El problema para su efectividad y que esa presencia equilibrada entre mujeres y hombres de las listas se vea reflejada en la composición de la Cámara es que más de dos tercios de los escaños provienen de circunscripciones pequeñas y medianas ${ }^{4}$ —en las que se eligen entre 2 y 9 escaños-, por lo que la presencia de mujeres entre las personas electas dependerá de su posicionamiento en los primeros puestos de las listas, ya que en estas circunscripciones sólo obtienen representación las primeras personas de las listas más votadas.

Para completar las elecciones a las Cortes Generales, es necesario referirse al sistema electoral operante para la configuración del Senado. En este caso, viene casi enteramente diseñado por el texto constitucional al determinar la composición de la Cámara en su art. 69. Así, se establece que en cada provincia se elegirán cuatro escaños al Senado por sufragio universal, libre, igual, directo y secreto, mientras que en las provincias insulares, cada isla o agrupación de ellas, con Cabildo o Consejo Insular, constituirá una circunscripción a estos efectos, correspondiendo tres a cada una de las islas mayores - Gran Canaria, Mallorca y

3 Presno Linera, M.A., «Régimen electoral (<maquiavélico >) y sistema de partidos (con sesgo mayoritario)», Revista Española de Derecho Constitucional, no 104, mayo-agosto 2015, pp. 13-48; y GuILLÉN LóPEz, E., «El sistema electoral del Congreso de los Diputados. Principios constitucionales y recientes propuestas de reforma», Revista Española de Derecho Constitucional, n ${ }^{\circ}$ 92, mayo-agosto 2011, pp. 203 y ss.

4 Para ello utilizaremos la distinción en tres tipos de circunscripciones en virtud de su tamaño realizada en Penadés, A. y Santiuste, S., Ob. Cit., p. 91. 
Tenerife - y uno a cada una de las siguientes islas o agrupaciones: Ibiza-Formentera, Menorca, Fuerteventura, Gomera, Hierro, Lanzarote y La Palma. Por su parte, Ceuta y Melilla elegirán cada una de ellas dos escaños al Senado. La composición se completa, más allá de la elección de escaños por sufragio, con la designación por parte de las Comunidades Autónomas de una persona y otra más por cada millón de habitantes de su respectivo territorio, realizado por parte de su Asamblea legislativa.

Es el art. 166.1 de la LOREG el que concreta el sistema de designación como mayoritario, especificando el modelo al determinar que las y los electores pueden dar su voto a un máximo de tres personas en las circunscripciones provinciales, dos en Gran Canaria, Mallorca, Tenerife, Ceuta y Melilla, y uno en las restantes circunscripciones insulares. Esta regulación no supone ninguna novedad respecto de lo que ya establecía el art. 21 del RDLNE.

Una vez realizado este breve recordatorio, resulta de especial interés el estudio del momento de determinación de estas normas, para poder observar cómo se concretaron y negociaron las mismas. Esto es así, por una parte, porque dentro de la teoría sobre los sistemas electorales, el estudio del momento de la creación de las normas resulta de especial relevancia ${ }^{5}$. Por otra parte, porque la doctrina especializada reconoce los sistemas electorales como instrumentos moldeables y con repercusiones directas en todo el sistema político y constitucional ${ }^{6}$.

Por ello, en el presente estudio se ha realizado un breve acercamiento a ese momento, a través del análisis de los debates parlamentarios que configuraron el modelo. Como hemos podido ver, las bases del sistema electoral operante en las Cortes Generales vienen establecidas por la Constitución. Así, centraremos el estudio en los diversos posicionamientos que tuvieron lugar, tanto en el Congreso como en el Senado, a lo largo del proceso de redacción definitiva del texto constitucional. Sin embargo, hemos podido ver cómo muchos de estos elementos del sistema ya se habían recogido en las normas electorales previas y que debían tener carácter de provisionalidad, como fueron la LRP y el RDLNE. De hecho, en ocasiones se ha tratado el debate en torno al sistema electoral desde la LRP, su concreción en el RDLNE, el proceso de elaboración de la Constitución y la definición en la LOREG como un único proceso prolongado en el tiempo ${ }^{7}$. Debido a ello, realizaremos un acercamiento previo a los debates de las Cortes franquistas en torno a la Ley para la Reforma Política.

Este ejercicio, que podríamos catalogar como «memoria histórica parlamentaria», nos permitirá poder concluir qué posturas diversas se defendieron, cómo

5 Picado León, H., «Implicaciones jurídicas del sistema electoral», Revista de Derecho Electoral, Tribunal Supremo de Elecciones, San José de Costa Rica, n6, segundo semestre 2008, p. 6.

6 Por ejemplo, puede verse en Lijphart, A., Sistemas electorales y sistemas de partidos: un estudio de veintisiete democracias, 1945-1990, Centro de Estudios Políticos y Constitucionales, Madrid, 1995.

7 Lago, I. y Montero, J.R., Ob. Cit., p. 280. 
los efectos que vendría a provocar el sistema electoral ya fueron previstos de algún modo $^{8}$ y cómo se llevaron a cabo las negociaciones para su concreción.

\section{ANTECEDENTES AL SISTEMA ELECTORAL CONSTITUCIONAL: LA LEY PARA LA REFORMA POLÍTICA}

La Ley 1/1977, de 4 de enero, para la Reforma Política, instrumento jurídico que sirvió para el paso «de la ley a la ley» en la Transición, ya perfiló los caracteres básicos que tendrían esas primeras elecciones que se realizarían para configurar las Cortes Generales tras la muerte del dictador.

Su art. 2.2 concreta que «Los Diputados del Congreso serán elegidos por sufragio universal, directo y secreto de los españoles mayores de edad», mientras que su art. 2.3 determina que "Los Senadores serán elegidos en representación de las Entidades territoriales». El apartado 4 de este mismo artículo establece el periodo de mandato en cuatro años. Por su parte, será la Disposición Transitoria Primera la que fije el marco de actuación del Gobierno al determinar la regulación de las primeras elecciones mediante Decreto, fijando los elementos fundamentales del sistema.

Centrando la atención en el proceso de elaboración de la norma, el 15 de octubre de 1976 el Consejo de Ministros remitió a las Cortes el Proyecto de Ley para la Reforma Política, que se publicaría en el Boletín Oficial de las Cortes Españolas $n^{\circ} 1532$ de 21 de octubre, conjuntamente con el Texto regulador del procedimiento de urgencia - procedimiento por el cual se tramitaría dicho Proyecto- - designación de la Ponencia encargada del Proyecto y el Informe del Consejo Nacional del Movimiento en referencia al mismo?. En este texto inicial propuesto por el Gobierno, las referencias al sistema electoral de la Disposición Transitoria Primera eran las siguientes:

«El Gobierno regulará las primeras elecciones a Cortes para constituir un Congreso de 350 diputados y elegir 204 senadores, a razón de cuatro por provincia, dos por Ceuta y dos por Melilla. Los senadores serán elegidos por sufragio universal directo y secreto de los españoles mayores de edad que residan en el respectivo territorio. Las elecciones al Congreso se inspirarán en criterios de representación proporcional Las elecciones al Senado se inspirarán en criterios de escrutinio mayoritario.»

Resulta conveniente la reproducción literal del texto inicial de cara a poder observar las diferencias existentes con respecto al resultado final tras el debate.

8 Presno Linera, M.A., «Crónica de una desproporcionalidad anunciada», en Estudios sobre la Constitución Española: homenaje al profesor Jordi Solé Tura, Vol. 1, Centro de Estudios Políticos y Constitucionales, 2008, pp. 859-874.

9 Boletín Oficial de las Cortes Españolas no 1532, de 21 de octubre de 1976, disponible en http:// www.congreso.es/docu/PHist/docs/8fran/1976/BOCE_1532.pdf (última consulta 4/11/2019). 
Así, podemos ver cómo nada se estipulaba respecto de la circunscripción electoral al Congreso, menos aún de una representación mínima inicial. Tampoco se preveía la incorporación de la barrera electoral para evitar fragmentaciones. Por tanto, todas ellas serán modificaciones que se introdujeron durante la tramitación del texto en las Cortes.

En primer lugar, cabe hacer mención al Informe del Consejo Nacional del Movimiento, el cual avala el Proyecto ya que lo entiende como «inserto dentro de un proceso de desarrollo político que iniciado el 18 de julio, va institucionalizando el poder político». En lo referente al sistema electoral, el Informe se pronuncia recogiendo que «cree recomendable el sistema mayoritario para ambas Cámaras, ya que sólo a través de él puede lograrse un número no excesivo de opciones políticas que permitan el adecuado funcionamiento de la democracia». Esta afirmación nos va a introducir en el hilo conductor básico del debate que tendrá lugar en las Cortes a este respecto.

Las enmiendas fueron debatidas en el Pleno los días 16, 17 y 18 de noviembre de 1976 y el contenido de los debates se publicó en el Diario de las Sesiones del Pleno, en un mismo número ${ }^{10}$. Los debates se inician con la defensa del Informe de la Ponencia por parte de Miguel Primo de Rivera y Urquijo. De esta intervención y respecto de nuestro objeto de estudio, cabe destacar dos cuestiones: por una parte, el posicionamiento para que las elecciones se regulen por el Gobierno y no proponer una Ley Electoral para no demorar el proceso; por otra, la aceptación de la incorporación de limitaciones al sistema electoral proporcional "para impedir la atomización de los grupos políticos que un sistema proporcional puro crearía, y así evitar los partidos más pequeños».

Pasando ya a las enmiendas y dejando de lado las enmiendas a la totalidad presentadas $^{11}$, trataremos de condensar las enmiendas defendidas en el Pleno en dos grandes grupos: las de contenido teórico o político y las de contenido práctico referido al procedimiento. Aunque sabemos que ningún elemento del sistema electoral, por técnico que parezca, resulta neutro a los objetivos políticos ${ }^{12}$, esta distinción clasificatoria nos permitirá orientar el contenido de los debates desarrollados. Respecto de aquellas enmiendas defendidas que podemos clasificar como políticas, podemos encontrar a su vez dos grandes grupos: por un lado aquellas que, como ya había recogido el Consejo Nacional del Movimiento, propugnaban la elección por criterios mayoritarios en ambas Cámaras; por otro lado

10 Cortes Españolas, Diario de Sesiones del Pleno, X Legislatura, no 29, disponible en http://www. congreso.es/docu/PHist/docs/8fran/1976/sesion16_17_18.pdf (última consulta 4/11/2019).

11 Siendo estas un total de tres, presentadas por los Procuradores Manuel María Escudero Rueda, Blas Piñar López y José María Fernández de la Vega y Sedano. Estas enmiendas se defendieron, contestaron y replicaron en la Sesión del día 16 de noviembre de 1976, siendo todas ellas rechazadas por la Ponencia.

12 Un repaso a los distintos enfoques teóricos realizados al respecto lo podemos encontrar en NoHLEN, D., «Controversias sobre sistemas electorales y sus efectos», Revista Española de Ciencia Política, $\mathrm{n}^{\circ} 31$, marzo 2013, pp. 9-39. 
aquellas que defendían el mantenimiento de la denominada «democracia» orgánica.

Teniendo en cuenta que el debate al que nos referimos tuvo lugar en el seno de las Cortes franquistas, no debería sorprender la defensa que por parte de un amplio número de Procuradores se hace de la composición orgánica de las Cámaras, a la vez que se alaban los «logros» del régimen franquista y del Movimiento Nacional. Sin embargo, este acercamiento permite de algún modo observar el sentido de las resistencias existentes para la aprobación de la propia Ley para la Reforma Política. En algunos casos, la defensa de la representación orgánica (empresarial, laboral, municipal o familiar) se propugna exclusivamente para el Senado $^{13}$. Sin embargo, en otras enmiendas, se reivindica este tipo de representación con carácter general ${ }^{14}$.

De especial interés resultan las enmiendas recogidas en el debate en defensa del sistema electoral mayoritario. Debido a ellas se establecen los correctivos a la proporcionalidad que se introdujeron en la redacción final y que, además, será una cuestión recurrente con posterioridad en los debates constituyentes, como veremos. En este sentido, se da un interesante debate entre quienes defienden el sistema proporcional ${ }^{15}$, quienes defienden las correcciones al sistema proporcional ${ }^{16}$ y quienes propugnan el sistema mayoritario ${ }^{17}$.

13 Cortes Españolas, Diario de Sesiones del Pleno, X Legislatura, $n^{\circ} 29$; en este sentido, Emilio Lamo de Espinosa y Enríquez de Navarra (p. 56); y Díaz-Llanos y Lecuona (p. 69).

14 Íbid; Raimundo Fernández-Cuesta y Merelo (pp. 78 y ss.), en cuya intervención critica ampliamente el sufragio universal e inorgánico como una ruptura con los Principios del Movimiento. De esta defensa queremos destacar lo siguiente, que aporta claridad a la posición defendida: «no queremos que se hagan reformas que, lejos de garantizar la concordia entre los españoles, vayan a romperla y puedan abrir puertas que faciliten en España la entrada del comunismo, que, se diga o se calle, es el verdadero peligro que se cierne sobre ella y sobre todo el mundo libre, y que avanza a pasos agigantados». También defiende la representación orgánica general Dionisio Martín Sanz (pp. 108 y ss.), que propugna también el establecimiento de circunscripciones electorales económico-sociales. Este Procurador retomará la cuestión tras las respuestas de la Ponencia (p. 183).

15 Íbid; así, David Pérez Puga (p. 76) defiende que «El fundamento de la representación proporcional es, pues, esencialmente un argumento de justicia porque ella sola permite representar al país según todas las tendencias que comporta». Por su parte, José Meilán Gil (pp. 117 y ss.) defiende que «Si hay algo que debe estimularse en la política española es la capacidad de diálogo, de negociación y de pacto, como corresponde a una sociedad que es plural. Si hay algo que creo que debe evitarse en las futuras Cortes es su radical enfrentamiento en dos bloques». Bernal Sánchez aporta otro argumento al debate (pp. 122 y ss.) al afirmar que «La configuración de las grandes corrientes políticas debe, sin embargo, realizarse a través de un proceso natural, uno de cuyos principales elementos estimulantes puede ser ciertamente la Ley Electoral. Pero el sistema proporcional es apto para desempeñar esta función». Finalmente, destaca la argumentación de Gabriel Cisneros Laborda (p. 127) defendiendo el sistema proporcional debido a la tarea constituyente que tendría que cumplir la futura Cámara.

16 Íbid; en este sentido, Carlos Iglesias Selgas (p. 43) defiende un sistema mixto «ya que la referencia a los dispositivos correctores para evitar la fragmentación puede permitir el que se maticen algunos de los aspectos que pueden ser más peligrosos del sistema de representación proporcional». Por su parte, Eugenio Lostau Román (p. 48) hace referencia a los «dispositivos correctores que, desde un punto de vista estadístico o matemático, a mí me parecen enormemente sensatos $y$ aceptables».

17 Íbid; podemos observar la defensa de Montserrat Tey Planas (p. 50) y de Cruz Martínez Esteruelas (pp. 89 y ss.), ya que entiende que "Con el sistema mayoritario se hace, pues, política de Estado y de gobierno; con la representación proporcional, se bace política de partido». 
Si hay un debate de especial trascendencia en el momento, es el que protagoniza el Procurador Cruz Martínez Esteruelas ${ }^{18}$. Tras haber realizado una ferviente defensa del sistema mayoritario y haber sido éste rechazado por parte de la Ponencia, en un segundo turno modifica su postura ${ }^{19}$. Así, se aviene a aceptar el sistema electoral proporcional, siempre y cuando queden claros algunos aspectos en la norma como "elementos correctores que puedan impedir que este país degenere en una situación ingobernable». En este sentido, "Sería preciso que la provincia (...), fuera circunscripción electoral exclusiva», además de que "no haya provincia de España, por pequeña que sea, que no tenga garantizado un número de Procuradores». Finalmente, exige que «se establezca que sea preciso un número mínimo de sufragios para acceder al Congreso». Tras ello, Fernando Sánchez González, en nombre de la Ponencia, recoge las propuestas realizadas y propone la redacción que sería la definitiva de la Disposición Adicional Primera ${ }^{20}$ —además de cambiar el número de escaños al Senado de 204 a 207 por la incorporación de las islas_- Esta fórmula es aceptada también, en nombre del Gobierno, por el Ministro de Justicia, Landelino Lavilla Alsina ${ }^{21}$. Esta modificación se aprueba en una primera votación ${ }^{22}$, que dará lugar al texto final sometido a votación que, como ya es sabido, fue aprobado definitivamente. La incorporación de estos elementos fue una exigencia de los líderes de Alianza Popular y se negoció directamente con estos para que mostraran su apoyo al texto propuesto ${ }^{23}$.

18 Aunque en estas Cortes no se realizaba una adscripción política, conviene realizar una breve pincelada biográfica del Procurador debido a la importancia de su aportación al texto definitivo. Cruz Martínez Esteruelas fue miembro de la dirección del Movimiento Nacional desde 1965, así como Ministro de Planificación del Desarrollo en 1973 y seis meses más tarde Ministro de Educación y Ciencia. Reseña biográfica de la Real Academia de Historia, disponible en http://dbe.rah.es/biografias/25509/cruz-martinez-esteruelas (última consulta 1/12/2019).

19 Cortes Españolas, Diario de Sesiones del Pleno, X Legislatura, n 29, pp. 173 y ss.

20 La redacción definitiva de la Disposición Adicional Primera quedó del siguiente modo:

«El Gobierno regulará las primeras elecciones a Cortes para constituir un Congreso de 350 diputados y elegir 207 senadores a razón de cuatro por provincia y uno más por cada provincia insular, dos por Ceuta y dos por Melilla. Los Senadores serán elegidos por sufragio universal, directo y secreto, de los españoles mayores de edad que residan en el respectivo territorio.

Las elecciones al Congreso se inspirarán en criterios de representación proporcional, conforme a las siguientes bases:

Primera. Se aplicarán dispositivos correctores para evitar fragmentaciones inconvenientes de la Cámara, a cuyo efecto se fijarán porcentajes mínimos de sufragios para acceder al Congreso.

Segunda. La circunscripción electoral será la provincia, fijándose un número mínimo inicial de Diputados para cada una de ellas.

Las elecciones al Senado se inspirarán en criterios de escrutinio mayoritario.»

21 Cortes Españolas, Diario de Sesiones del Pleno, X Legislatura, n 29, p. 197, «...el Gobierno acepta plenamente la fórmula de la Ponencia, que ha sido establecida al final de la intervención del Ponente señor Suárez».

22 Votación en la que quienes estaban de acuerdo permanecían en sus asientos, y se levantaban sucesivamente quienes estaban en contra y quienes se abstenían. Así, se aprueba con 2 votos en contra y 57 abstenciones.

23 De Carreras, F. y Vallés, J.M., Las Elecciones, Ed. Blume, Barcelona, 1977, p. 311. También se encuentra un análisis de esta negociación en URDÁNOZ, J., «El origen del modelo representativo de la Constitución de 1978», Revista de Estudios Políticos, n 186, 2019, pp. 13-44. 
Como ya se había apuntado, tras las bases determinadas por la Ley para la Reforma Política, será el Real Decreto-ley 20/1977, de 18 de marzo, sobre Normas Electorales la norma que termine de perfilar el sistema electoral ${ }^{24}$. Sobre esta última norma no existen debates, ya que su elaboración correspondió directamente al Gobierno - aunque se realizaron consultas con representantes de la oposición ${ }^{25}$ Sin embargo, sí es conocido que el sistema se configuró por parte de los miembros del Gobierno con base en las encuestas electorales y de forma que el sistema beneficiara a sus intereses (de ahí el sesgo conservador) y con la apariencia de negociación debida a las consultas realizadas ${ }^{26}$.

\section{LOS DEBATES CONSTITUCIONALES EN EL CONGRESO}

A pesar de que la configuración definitiva del sistema electoral a la Cortes Generales recogería la realizada previamente por las normas citadas ${ }^{27}$, tanto la LRP como el RDLNE, eran normas provisionales que tendrían que regir durante un periodo concreto. Por ello, el sistema electoral tendría que establecerse para el nuevo sistema constitucional en el propio texto de la CE. A continuación, centraremos el análisis en los debates y las enmiendas que tuvieron lugar en el Congreso de los Diputados respecto del sistema electoral al Congreso y al Senado durante el proceso de elaboración de la Constitución, los cuales fueron fruto de diversas redacciones en cada una de las fases, enmiendas y debates. Es importante tener en cuenta en este caso que, a diferencia de la situación existe en la elaboración del RDLNE en la que no se conocían los apoyos con que contaba cada partido, en este momento de redacción constitucional ya ha habido un proceso electoral que ha permitido que cada uno de los grupos sea consciente de su apoyo electoral y su capacidad de negociación.

\section{Anteproyecto constitucional}

El Boletín Oficial de las Cortes $n^{\circ} 44$, de 5 de enero de $1978^{28}$ publicaba el texto del Anteproyecto de Constitución elaborado por la Ponencia, así como los Votos particulares formulados.

24 Un análisis de la norma en SÁnchez Agesta, L., Ley Electoral. Real Decreto Ley sobre Normas Electorales, Editoriales de Derecho Reunidas, Madrid, 1977.

25 Íbid, p. 312.

26 Un análisis sobre el proceso de configuración de las normas electorales puede verse en LAGO, I. y Montero, J.R., Ob. Cit., pp. 299-301.

27 Pérez-Serrano Jáuregui, N., «Artículo 68. El Congreso de los Diputados», en Alzaga Villaamil, O., Comentarios a las Leyes Políticas. Constitución Española de 1978, Tomo IV, Editoriales de Derecho Reunidas, Madrid, 1989, p. 114. El autor califica el art. $68 \mathrm{CE}$ como «bijo legítimo y heredero universal» de las normas citadas.

28 Disponible en http://www.congreso.es/public_oficiales/L0/CONG/BOCG/BOC_044.PDF (última consulta 4/11/2019). 
Este texto recogía el sistema electoral al Congreso de los Diputados en su art. $59^{29}$. Esta redacción mantenía el contenido del art. 58 del Borrador de la Ponen$\mathrm{Cia}^{30}$, aunque habiendo suprimido el anterior apartado 3 , que establecía que: «El Congreso se integra por un Diputado por cada 75.000 babitantes o fracción superior a 40.000 a distribuir con arreglo a la población en los términos que establezca la Ley electoral». Esta supresión demuestra que la actitud inicial en la Ponencia fue la de no constitucionalizar ningún sistema electoral ${ }^{31}$.

Los Votos particulares ${ }^{32}$ que se refirieron a la redacción de este artículo, se desarrollan en dos sentidos: por una parte, en recoger expresamente la referencia al sistema de elección proporcional; por otra, en recuperar la distribución de escaños en virtud de la población, en el sentido en que lo hacía el apartado 3 del art. 58 del Borrador, y que había sido suprimido en el art. 59 del Anteproyecto.

Respecto de la composición y elección del Senado, el texto del Anteproyecto recogía su configuración en su art. $60^{33}$ que se tiene que observar con relación a la introducción de una Disposición Transitoria Quinta con la siguiente redacción:

29 Art. 59 del Anteproyecto de Constitución:

«1. Los Diputados del Congreso se eligen por sufragio universal, libre, igual, directo y secreto.

2. El Congreso es elegido por cuatro años. El mandato de los Diputados termina cuatro años después de su elección o el día de la disolución de la Cámara.

3. Son electores y elegibles todos los españoles mayores de edad que estén en el pleno uso de sus derechos políticos. La Ley reconocerá y el Estado facilitará el ejercicio del derecho de sufragio a los españoles que se encuentren fuera del territorio de España.»

30 Las actas de la Ponencia Constitucional, así como el texto del borrador, se publicaron en 1984 (ya que el carácter secreto de los debates impidió su publicación oficial) en la Revista de la Cortes Generales, $\mathrm{n}^{\circ} 2$, disponible en http://www.congreso.es/constitucion/ficheros/actas/actas.pdf (última consulta $10 / 11 / 2019)$.

31 Alzaga Villaamil, O., La Constitución española de 1978 (comentario sistemático), Ediciones del Foro, Madrid, 1978, p. 447.

32 Boletín Oficial de las Cortes n ${ }^{\circ} 44$, de 5 de enero de 1978; así se recoge en los Votos particulares del Grupo Parlamentario Comunista (Jordi Solé Tura, p. 705), del Grupo Parlamentario de la Minoría Catalana (Miquel Roca Junyent, p. 710) y del Grupo Parlamentario Socialistas del Congreso (Gregorio Peces-Barba Martínez, p. 717).

33 Art. 60 del Anteproyecto:

«1. El Senado se compone de los representantes de los distintos Territorios Autónomos que integran España.

2. Los Senadores serán elegidos por las Asambleas legislativas de los Territorios Autónomos, entre sus miembros, por un periodo igual al de su propia legislatura, con arreglo a un sistema de representación proporcional y de manera que se asegure la representación de las diversas áreas del Territorio.

3. Cada Territorio Autónomo designara diez Senadores y otro más por cada quinientos mil habitantes o fracción superior a doscientos cincuenta mil habitantes. Ningún Territorio Autónomo podrá designar un número de Senadores igual o mayor al doble del número de Senadores que corresponda a otro Territorio Autónomo.

4. Al comienzo de cada legislatura, e1 Congreso de los Diputados, por mayoría de tres quintos de votantes que represente, al menos, la mayoría absoluta de la Cámara, podrá elegir hasta veinte Senadores de entre personas que hubieran prestado servicios eminentes en la vida cultural, política, económica o administrativa de España.» 
"Las provincias que no se hayan constituido en Territorio Autónomo estarán representadas en el Senado, mediante Senadores elegidos por la totalidad de los Concejales de todos sus municipios, a razón de dos Senadores por provincia y uno más por cada quinientos mil habitantes.»

Esta redacción se inspira en la contenida en el Borrador - entonces art. 59 - la cual fue encargada por la propia Ponencia a los letrados, aunque modifica alguno de sus contenidos iniciales, como las referencias a las provincias de los Territorios Autónomos, a las condiciones de quienes pudieran ser elegibles y al número de habitantes por escaño al Senado elegido por la Asamblea ${ }^{34}$.

En este caso, los Votos particulares relacionados con este artículo, hacen referencia a las siguientes cuestiones: por una parte, suprimir el párrafo 4, sobre la elección de escaños al Senado por parte del Congreso, además de recoger la elección por las provincias referidas en la Disposición Transitoria de entre los concejales $^{35}$; por otra parte, en recuperar la redacción inicial del Borrador -elección de un escaño por Territorio Autónomo, uno más por provincia y otro por cada 250.000 habitantes_ ${ }^{36}$.

Por su parte, la Comisión de Asuntos Constitucionales y Libertades Públicas introdujo 779 escritos de enmiendas al texto del Anteproyecto ${ }^{37}$, de los cuales 52 se referían a los artículos mencionados, y sobre las que se pronunciaría la Ponencia.

34 Art. 59 del Borrador:

"1. Los Senadores serán elegidos por las Asambleas legislativas de los Territorios Autónomos por un periodo igual al de la propia legislatura, con arreglo a un sistema de representación proporcional y a razón de un Senador por cada Territorio Autónomo, uno más por cada una de las provincias existentes en el momento de la promulgación de la Constitución en el integrados y uno más por cada 250.000 habitantes of fracción superior a 125.000 .

2. Salvo disposición en contrario del respectivo Estatuto de Autonomía, los Senadores no habrán de ostentar la condición de miembros de la Asamblea Legislativa que los elige, pero sí reunir las condiciones de elegibilidad necesaria pare formar parte de la misma.

3. Al comienzo de cada Legislatura, el Congreso, por mayoría de 3/5 de votantes que represente al menos la mayoría absoluta de la Cámara podrá elegir hasta veinte Senadores de entre personas que hubieran prestado servicios eminentes a la culture, la política, la economía (¿o las armas?) de España.

4. Disposición Transitoria. En aquellas provincias (aún) no integradas en un Territorio Autónomo se elegirá un Senador por cada provincia y otro más por cada 20.000 habitantes of fracción superior a 125.000. Serán electores todos los concejales de los Municipios que constituyen la provincia y elegibles quienes reúnan las condiciones para ser elegidos concejales. El mandato de los así elegidos tendrá una duración de cuatro años.»

35 Boletín Oficial de las Cortes $n^{\circ} 44$, de 5 de enero de 1978; en este sentido se pronuncia el Voto Particular del Grupo Parlamentario Comunista (Jordi Solé Tura, pp. 705 y 708). Respecto de la Disposición Transitoria, se adhieren los Votos Particulares del Grupo Parlamentario de la Minoría Catalana y del Grupo Parlamentario Socialistas del Congreso.

36 Íbid; así lo recogen los Votos particulares del Grupo Parlamentario de la Minoría Catalana (Miquel Roca Junyent, p. 710) y del Grupo Parlamentario Socialistas del Congreso (Gregorio Peces-Barba Martínez, p. 717).

37 Documento disponible en http://www.congreso.es/constitucion/ficheros/enmiendas/enmcongreso. pdf (última consulta 10/11/2019). 


\section{Enmiendas e Informe de la Ponencia}

A) Sobre el art. 59: enmiendas y decisión de la Ponencia

Dejando de lado las enmiendas referidas a cuestiones de redacción o de procedimiento — como aquellas relativas a plazos o convocatoria—, podemos distinguir dos enmiendas básicas a este artículo ${ }^{38}$ :

- Enmiendas que buscan la referencia expresa a la proporcionalidad en el sistema electoral del Congreso de los Diputados. En este sentido, las enmiendas presentadas por el Grupo Parlamentario (en adelante, GP) de la Minoría Catalana, al que se adhiere el Diputado Letamendia Belzunce de Euskadiko Eskerra (Grupo Mixto); por el GP Socialistes de Catalunya; el GP Socialistas del Congreso; el GP Mixto y el GP Comunista.

- Enmiendas que buscan fijar una relación directa entre escaños y población, recogiendo la redacción ya prevista en el Borrador de un escaño por cada 75.000 habitantes o fracción superior a 40.000. Con este contenido se presentan las enmiendas del GP de la Minoría Catalana, al que se adhiere el Diputado Letamendia Belzunce de Euskadiko Eskerra (Grupo Mixto); del GP Socialistes de Catalunya; del GP Socialistas del Congreso; del GP Mixto y del GP Comunista.

La Ponencia, tal y como recoge su informe ${ }^{39}$, sólo aceptará finalmente aquellas enmiendas referidas al procedimiento, plazos y convocatoria. Respecto del contenido de las enmiendas anteriormente citadas —inclusión específica de la proporcionalidad y relación de escaños y población-, son rechazadas manteniendo el texto del anteproyecto con los únicos votos de UCD y AP. Por su parte, las modificaciones introducidas lo son por unanimidad. Con ello, el texto resultante de estos trabajos corresponderá ahora al art. 63 del texto ${ }^{40}$.

38 También se presenta una enmienda que reclama la asunción del escrutinio mayoritario en el sistema electoral del Congreso de los Diputados (por el Diputado López Rodó, de AP) y otra enmienda que solicita la supresión del apartado 3 del artículo por entenderlo reiterativo del art. 23 (del Diputado Carro Martínez, de AP).

39 Boletín Oficial de las Cortes, $\mathrm{n}^{\circ} 82$, de 17 de abril de 1978, disponible en http://www.congreso.es/ public_oficiales/L0/CONG/BOCG/BOC_082.PDF (última consulta 10/11/2019).

40 Art. 63 del Anteproyecto del Informe de la Ponencia:

«1. Los Diputados del Congreso se eligen por sufragio universal, libre, igual, directo y secreto.

2. El Congreso es elegido por cuatro años. El mandato de los Diputados termina cuatro años después de su elección o el día de la disolución de la Cámara.

3. Son electores y elegibles todos los españoles que estén en pleno uso de sus derechos políticos.

4. Las elecciones tendrán lugar entre los 30 días y 60 días, de la terminación del mandato. El Congreso electo deberá ser convocado dentro de los 25 días siguientes a la celebración de las elecciones.» 
B) Sobre el art. 60: enmiendas y decisión de la Ponencia

Las enmiendas presentadas a este artículo del Anteproyecto, referido al sistema electoral y composición del Senado fueron más amplias y variadas. Las mismas las podemos agrupar del siguiente modo:

- Enmiendas relativas al número de escaños a elegir por las Asambleas de cada territorio autónomo. Dentro de este grupo, las opciones propuestas fueron diversas. La elección de un escaño por territorio, otro por provincia y otro por cada 250.000 habitantes o fracción ${ }^{41}$; la elección de cinco escaños por territorio, otro por provincia y otro por cada 250.000 habitantes o fracción ${ }^{42}$; elección de 10 escaños por territorio y otro por cada 500.000 habitantes o fracción ${ }^{43}$; o incluso el mismo número de escaños correspondientes a cada territorio. También formarían parte de este grupo aquellas enmiendas orientadas a eliminar la limitación establecida por el párrafo 3 del artículo (límite del doble de escaños entre unos y otros territorios) $)^{44}$.

- Enmiendas relativas a la supresión del párrafo 4 sobre la designación de escaños al Senado por el Congreso. En este sentido, el GP de la Minoría Catalana, el Diputado Letamendia Belzunce de Euskadiko Eskerra (Grupo Mixto), el GP Socialistes de Catalunya el GP Socialistas del Congreso, el GP Mixto y el GP Vasco.

- Recuperar la previsión del art 2.3 de la LRP e incorporar designaciones realizadas por el Rey. En la enmienda presentada por el Diputado López Rodó (GP de AP).

- La designación de escaños también por las islas. Enmienda conjunta presentada por los Diputados Clar Garau, Rodríguez-Miranda, Durán Pastor y Gari Mir (GP de UCD).

- Cambiar la denominación de territorios por la de regiones. En este sentido, por ejemplo, los Diputados Ortí Bordás (GP de UCD), el Diputado López Rodó (GP de AP), y el apoyo del Diputado Jarabó Payá (GP de AP).

De especial interés resulta, por cuanto sería la redacción más similar al resultado final, la enmienda presentada por el Diputado Ortí Bordás (GP de UCD),

41 Enmienda de GP de la Minoría Catalana y enmienda de adhesión del GP Mixto al Voto Particular del GP Socialistas del Congreso.

42 Así las enmiendas del Diputado Letamendia Belzunce de Euskadiko Eskerra (Grupo Mixto) y del Diputado Guerra Fontana (GP Socialistes de Catalunya).

43 En este sentido el Diputado Ortí Bordás (GP de UCD), el Diputado López Rodó (GP de AP), el Diputado Carro Martínez (GP de AP), el Diputado López Raimundo (GP Comunista) y el apoyo del Diputado Jarabó Payá (GP de AP).

44 Así lo recoge la enmienda presentada por el GP Vasco y por el Diputado Jarabó Payá (GP de AP). 
que recogía que "Los Senadores serán elegidos por sufragio libre, igual, directo y secreto, por un periodo de cuatro años y con arreglo a un sistema escrutinio mayoritario que asegurará la representación de las diversas provincias y comarcas de la región».

La Ponencia, en el caso de este artículo, opta por no pronunciarse sobre ninguna de las enmiendas presentadas. Respecto de las enmiendas relacionadas con la denominación y la terminología empleada, la Ponencia entiende que quedan sin objeto, ya que la misma ha sido aclarada por la nueva redacción del Título VIII. Respecto del resto de enmiendas, la Ponencia se pronuncia diciendo que «Dada la complejidad de la cuestión, de la que es buena muestra el número de enmiendas presentadas, y su conexión necesaria con la redacción que finalmente se acuerde para el Título VIII, la Ponencia ha juzgado preferible la supresión de estos apartados, remitiendo la determinación de la composición concreta del Senado a una ley orgánica, cosa que se hace en el apartado anterior. No se ha pronunciado, en consecuencia, ni en favor ni en contra de las enmiendas presentadas». Por tanto, no se pronuncia sobre ninguna de ellas y suprime la mayor parte del artículo, quedando éste como nuevo artículo 64 y con la siguiente redacción:

"El Senado se compone de los representantes de las diferentes entidades territoriales que integran España en los términos que determine la ley orgánica.»

\section{Debates en la Comisión de Asuntos Constitucionales y Libertades Públicas}

Estos debates tendrían lugar, tras el Informe de la Ponencia, entre los días 5 de mayo y 20 de junio de 1978. El primero de los días se llevaron a cabo las intervenciones generales referidas a la totalidad del texto presentado ${ }^{45}$. En relación con el objeto que nos ocupa, podemos destacar la defensa del Diputado Carrillo Solares (en calidad de portavoz del GP Comunista) en torno a que tanto la composición del Congreso y del Senado, como los criterios electorales se encuentren recogidos en la Constitución, quedando así fuera de la posibilidad de modificación por parte de las diversas mayorías que pudieran existir en el supuesto de su regulación legislativa. Esta intervención contrasta, evidentemente, con la del Diputado Fraga Iribarne (en calidad de portavoz del GP de Alianza Popular), en la que se refiere a una ley electoral cuyo objetivo tendría que ser la de favorecer la creación de dos grandes bloques políticos. El resto de intervenciones generales referidas al Senado hicieron hincapié en la insuficiente regulación del mismo y en la necesidad de solucionar la escueta referencia constitucional contenida en el Anteproyecto tras el Informe de la Ponencia ${ }^{46}$.

45 Diario de Sesiones del Congreso de los Diputados, n 59, Comisión de Asuntos constitucionales y libertades públicas, sesión n ${ }^{\circ}$ 1, 5 de mayo de 1978, disponible en http://www.congreso.es/public_oficiales/ L0/CONG/DS/C_1978_059.PDF (última consulta 4/11/2019).

46 Así se pronuncian los Diputados Raventós Carner (GP Socialistes de Catalunya), Peces-Barba Martínez (GP Socialistas del Congreso) y Barrera Costa (Ezquerra Catalana, del Frente Electoral Democrático). 


\section{A) El único debate pospuesto y el «consenso» externo a la Comisión}

Antes de entrar a analizar el contenido concreto de los debates, cabe destacar que en relación con estos, en torno a los artículos que nos ocupan, ocurre un hecho particular respecto del debate que tuvo lugar con el resto del articulado. Y es que el mismo no se desarrolló en el orden previsto, sino que se pospuso para el final del debate. Así, mientras que la defensa de parte de las enmiendas se realizó el 1 de junio, el GP Socialistes de Catalunya ${ }^{47}$ propuso aplazar el resto del debate y votación "basta que madure el debate, discusión y votación en su momento, de los artículos que pueden condicionar la configuración definitiva de las Cámaras y de las Cortes Generales», especialmente referido a la organización territorial del Estado. Esta propuesta fue aceptada y el resto del debate y la votación se produjeron al final, cuando ya se había consensuado el resto del texto constitucional, el día 20 de junio de 1978.

Si atendemos al contenido de los debates en la Comisión de este último día ${ }^{48}$, observamos cómo el trabajo sobre este artículo 63 se había ya realizado de manera paralela, mediante propuestas y acuerdos que no hemos podido conocer hasta el momento $^{49}$. Lo que ocurre en esta sesión es que el GP Socialistas en el Congreso, a través del Diputado Peces-Barba Martínez, presenta una enmienda in voce proponiendo la redacción que finalmente sería aprobada por la Comisión - y prácticamente igual a la actual_- Paralelamente, el resto de Grupos y Diputados que habían propuesto enmiendas al artículo las retiran. El único grupo que mantiene su postura previa y defiende el texto de la ponencia es el GP de Alianza Popular, a través de su Diputado Fraga Iribarne. Con todo ello, pasamos de un sistema de desconstitucionalización del sistema electoral al Congreso de los Diputados acordado entre AP y UCD en la Ponencia constitucional, a otro sistema donde se constitucionalizan los elementos básicos por acuerdo de todos los grupos excepto $\mathrm{AP}^{50}$. Por todo ello, reconocería el Diputado Fraga Iribarne posteriormente, en el debate que tendría lugar en el Pleno del Congreso de los Diputados, que este habría sido «el artículo en el cual fue más difícil el tal «consenso»» ${ }^{51}$.

47 Diario de Sesiones del Congreso de los Diputados, $n^{\circ} 78$, Comisión de Asuntos constitucionales y libertades públicas, sesión n ${ }^{\circ}$ 14, 1 de junio de 1978, intervención del Diputado Martín Toval (GP Socialistes de Catalunya), p. 2855. Disponible en http://www.congreso.es/public_oficiales/L0/CONG/DS/C_1978_078. PDF (última consulta 14/11/2019).

48 Diario de Sesiones del Congreso de los Diputados, n 93, Comisión de Asuntos constitucionales y libertades públicas, sesión n 24, 20 de junio de 1978, disponible en http://www.congreso.es/public_oficiales/ L0/CONG/DS/C_1978_093.PDF (última consulta 14/11/2019).

49 La existencia de «trabajos noctámbulos para consensuar textos» se reconoce en AlzaGa VillaAmil, O., «El proceso constituyente español visto por uno de sus protagonistas: entrevista a Óscar Alzaga Villaamil», Historia Constitucional, n ${ }^{\circ} 19,2018$, pp. 1-16.

50 El acuerdo de todos los grupos, excepto AP, se observa en la retirada de enmiendas y en la votación final del artículo. También se reconoce así en Alzaga Villaamil, O., La Constitución..., Ob. Cit., pp. 445 y ss.

51 Diario de Sesiones del Congreso de los Diputados, $\mathrm{n}^{\circ} 108$, Sesión plenaria $\mathrm{n}^{\circ} 37,12$ de julio de 1978, p. 4180. Disponible en http://www.congreso.es/public_oficiales/L0/CONG/DS/C_1978_108.PDF (última consulta 15/11/2019). 
Tras este acuerdo externo de los grupos, quedó finalmente redactado el artículo $63^{52}$ por la Comisión y reflejado en su Dictamen ${ }^{53}$.

Algo similar ocurriría con el caso del art. 64, referido a la composición y elección del Senado. En este sentido, el día 20 de junio se presentaría por parte del GP de UCD, a través de su Diputado Alzaga Villaamil una enmienda in voce, consensuada en este caso sin el acuerdo del GP Comunista. En este caso no fue necesario retirar expresamente las enmiendas defendidas por el resto de grupos, ya que tal defensa no se había producido el día 1 de junio, como sí había ocurrido con el debate del art. 63. Sin embargo, sí se votarían otras enmiendas, que veremos a continuación, entre las que se incluye la propuesta por el Diputado Gastón Sanz (GP Mixto) y que se aprobaría por unanimidad, para introducir el periodo de cuatro años como mandato en el Senado. Con todo ello, el Informe de la Comisión recogería la nueva redacción del art. $64^{54}$.

\section{B) Debates sobre el art. 63: el Congreso de los Diputados}

El hecho de que hayamos recogido el resultado final de la Comisión previamente, de cara a clarificar lo inusual de la metodología utilizada, no impide que prestemos atención a los debates que tuvieron lugar en la Comisión en torno al sistema electoral.

52 Art. 63 en el Dictamen de la Comisión del Congreso:

«1. El Congreso se compone de un mínimo de 300 y un máximo de 400 Diputados, elegidos por sufragio universal, libre, igual, directo y secreto, en los términos que establezca la ley.

2. La circunscripción electoral es la provincia. La ley distribuirá el número total de Diputados, asignando una representación mínima inicial a cada circunscripción y distribuyendo los demás en proporción a la población.

3. La elección se verificará en cada circunscripción atendiendo a criterios de representación proporcional.

4. El Congreso es elegido por cuatro años. El mandato de los Diputados termina cuatro años después de su elección o el día de la disolución de la Cámara.

5. Son electores y elegibles todos los españoles que estén en pleno uso de sus derechos políticos. La ley reconocerá y el Estado facilitará el ejercicio del derecho de sufragio a los españoles que se encuentren fuera del territorio de España.

6. Las elecciones tendrán lugar entre los treinta días y sesenta días de la terminación del mandato. El Congreso electo deberá ser convocado dentro de los veinticinco días siguientes a la celebración de las elecciones.»

53 Boletín Oficial de las Cortes, $\mathrm{n}^{\circ} 121$, de 1 de julio de 1978, disponible en http://www.congreso.es/ public_oficiales/L0/CONG/BOCG/BOC_121.PDF (última consulta 15/11/2019).

54 Art. 64 en el Dictamen de la Comisión del Congreso:

«1. El Senado se compone de cuatro Senadores elegidos por los votantes de cada provincia en los términos que señala una ley orgánica.

2. Las Comunidades Autónomas que se constituyan podrán proponer, de acuerdo con lo que señalen sus Estatutos, en el marco de una ley orgánica, dos candidatos a Senadores que serán nombrados por el Rey. Este número se reducirá a uno en el caso de las Comunidades Autónomas cuyo ámbito no supere el de una provincia.

3. La ley orgánica que, de acuerdo con lo dispuesto en los apartados a) y c) del artículo 142 autorice la constitución de las Comunidades Autónomas o de los territorios de régimen autonómico, fijará la representación de los mismos en el Senado.

4. El Senado es elegido por cuatro años." 
Nos referiremos a continuación a las intervenciones y defensas realizadas de las enmiendas en la sesión del día 1 de junio de 1978. Respecto del sistema electoral al Congreso de los Diputados, el debate fundamental gira en torno a la idea de proporcionalidad - tanto en su acepción relativa al sistema de elección proporcional, como a su acepción relativa a la distribución proporcional de escaños por población ${ }^{55}$ - Tengamos en cuenta que el texto surgido del Informe de la Ponencia - decidido por acuerdo de los representantes de AP y UCD- no recoge nada al respecto; éste será el objetivo del resto de grupos, la inclusión de la proporcionalidad en el texto del artículo.

De todos los debates desarrollados en torno a la cuestión a lo largo del proceso de elaboración de la Constitución — de los que tenemos transcripción-, los que tuvieron lugar en el seno de la Comisión del Congreso serían los de mayor interés, por cuanto se pueden observar los diversos posicionamientos políticos de cada grupo. No podemos olvidar que éste es uno de los artículos esenciales, no sólo de la Constitución, sino de todo el sistema constitucional generado a partir de ella. Estos diversos posicionamientos de cada grupo obedecen a esa centralidad y, especialmente, a su repercusión en los intereses electorales futuros de cada uno.

Inicia el debate el Diputado Martín Toval (GP Socialistes de Catalunya) ${ }^{56}$ con la defensa de la enmienda presentada para añadir al apartado 1 que «los Diputados del Congreso representan al pueblo español en su conjunto». Además de ello, «mayor interés, mayor importancia, mayor, si se quiere, disenso político, comporta la siguiente alternativa que pretendemos introducir en este párrafo 1. Se refiere explícitamente al añadido «in fine» al texto de la Ponencia, que serán elegidos los Diputados al Congreso con arreglo a un sistema de representación proporcional», mediante lo cual «no pretendemos sino constitucionalizar aquel sistema electoral que es el más adecuado a la representación de todas las fuerzas politicas y, por tanto, a la representación de todas las ideologias que representan el sentir del pueblo en su conjunto».

Esta enmienda sería respondida contrariamente por el Diputado Fraga Iribarne (GP de AP) defendiendo el texto de la Ponencia. Durante su intervención sostiene que la Constitución sólo recoja principios generales, dejando así flexibilidad al legislador para evitar reformas constitucionales. Deja claro que prefiere el sistema mayoritario, pero en cualquier caso plantea no constitucionalizar ningún modelo para permitirle hacerlo al legislador, ya que defiende la búsqueda de un mecanismo que posibilite «Gobiernos eficaces y estables y también oposiciones responsables, lo que es bien sabido que no todos los sistemas electorales producen exactamente por igual». Esta intervención es muy destacable en su contenido teórico respecto de la representación y la identidad, pudiendo destacar el fragmento en el que se

55 Diario de Sesiones del Congreso de los Diputados, $\mathrm{n}^{\circ} 78$, Comisión de Asuntos constitucionales y libertades públicas, sesión $\mathrm{n}^{\circ}$ 14, 1 de junio de 1978; sobre esta dualidad puede verse la intervención del Diputado Fajardo Spínola (GP Socialistas del Congreso) y del Diputado Martín Toval (GP Socialistes de Catalunya), pp. 2837 y 2853.

56 Íbid, pp. 2828 y 2829. 
afirma que "Ninguna representación puede ser exacta. No bay ningún sistema perfecto, y todos los intentos de acercarse a dicha representación perfecta pasarán siempre por el becho de que la combinación de las dos ideas, de delegación e identidad, nos llevan a imperfecciones, y los que votan, que son siempre un grupo del país y no todo, ya que no votan los menores, los incapaces, las personas excluidas por la ley de derecho de voto, representan a los que votan y a los que no votan. Más aún. Como siempre, cualquiera que sea el sistema, quedarán cocientes no representados, y los electos, a su vez, representan a quienes no les eligieron, pues, como se ba dicho con acierto, representan al conjunto del país. Por lo tanto, al establecer un sistema de representación tenemos que buscar dos cosas: por una parte la justicia y la congruencia sociológicas. Dentro de esa necesidad de imperfecciones en el sistema representativo tiene que haber una dosis de justicia, palabra que siempre me ha parecido clave dentro del Derecho y, por lo mismo, en alguna enmienda «in voce» posiblemente se pudiera añadir de algún modo para dar un criterio interpretativo al Tribunal Constitucional a la hora de medir una ley electoral. Hace falta la congruencia sociológica, y en eso, evidentemente, los números puros y simples no son suficiente. Qué duda cabe que la realidad geográfica, la realidad comarcal, la de un valle aislado, la de una isla, por ejemplo, pueden y deben aconsejar correcciones importantes al mero principio de la pura proporcionalidad numérica» ${ }^{57}$. Este último párrafo en la intervención del Diputado es muy revelador, si tenemos en cuenta la configuración del sistema electoral previsto, tanto anteriormente en las normas preconstitucionales citadas, como posteriormente en su redacción definitiva. Por una parte, se habla de la «congruencia sociológica», que nos recuerda a la defensa de la organicidad en los debates ya vistos en el marco de la LRP. Pero además, se defienden las correcciones geográficas al sistema electoral. Estas correcciones geográficas están actualmente previstas en el sistema electoral mediante el establecimiento de la circunscripción provincial con asignación mínima de escaños. Por tanto, podemos concluir de esta aportación que estas previsiones geográficas, efectivamente actúan como correcciones al sistema electoral proporcional. El tiempo y los resultados electorales desde entonces confirman que así actúan estos elementos: aportando un claro sesgo mayoritario al sistema electoral.

Continúa el Diputado Tierno Galván (GP Mixto) con la defensa también de la inclusión en el apartado 1 de "Con arreglo a un sistema de representación proporcional» ${ }^{58}$. Su intervención versa sobre el sentido de la palabra "proporcionalidad», la cual no es una simple cuestión aritmética. Así, defiende que «Parece que los argumentos giran en darle a la expresión «proporcional» un sentido que se le está concediendo, yo diría que con cierta arbitrariedad. Al emplear la expresión "proporcionalidad» quedan abiertas para una futura ley todas las posibilidades, ya que no sabemos a qué va a ser proporcional, y esto puede decirlo después el legislador, si ha de ser proporcional al territorio, si ha de ser también a los habitantes, si ha de ser proporcional a la desigualdad

57 Íbid, p. 2830.

58 Íbid, p. 2832. 
que existe entre los diversos territorios que constituyen el Estado. Eso queda absolutamente abierto y no se prefigura, me parece, con proporcionalidad, cuál es la relación de proporcionalidad». De forma clarificadora, continúa afirmando que «Es obvio que los intereses de Partido aconsejan defender el voto, bien en las ciudades con gran cantidad de obreros industriales, bien en el campo, en donde el obrero industrial es menor y, por consiguiente, la inclinación de voto es distinta. Es sabido que en las grandes ciudades la inclinación de voto oscila a posiciones menos conservadoras, y en el campo la inclinación de voto es a posiciones más conservadoras. Natural es que aquellos que tienen puesta su confianza electoral, digamos, en la conclusión electoral en las pequeñas ciudades rurales, en las aldeas, están temerosos de que proporcionalidad signifique un cierto criterio rígido y aritmético; pero también es natural que entendamos que quienes están confiando en las grandes ciudades con base proletaria estén deseosos de que se mantenga un sentido que tenga mayor preferencia de carácter numérico o aritmético. Pero, entre ambos casos, la percepción y la óptica no es la serena, digamos que no es la equilibrada, porque se está prejuzgando que proporcional va a definir la ley consecuente». Por ello, considera que este puede ser objeto de estancamiento que podría solucionarse con la introducción de algún elemento «aproporcional». Esta intervención del Diputado Tierno Galván es destacable por cuanto plasma la realidad de los diversos posicionamientos en torno al sistema electoral: los intereses partidistas. Como ya se ha dicho anteriormente, el sistema electoral es un instrumento manipulable dentro de cualquier ordenamiento constitucional y se observa en este proceso de negociación cómo las diversas posturas obedecen a defensas de aquellas cuestiones más beneficiosas para cada orientación política. Y claramente la cuestión geográfica en un Estado como el español es fundamental. Se deja así reconocido en estos debates que la orientación política del voto tiene mucha relación con su ubicación geográfica y de ahí la importancia de que el modelo finalmente resultante reconozca en mayor o menor medida el voto urbano o rural, de zonas con gran población o despobladas. Esta cuestión también se ha podido ver, ya con el tiempo y los resultados electorales, como una realidad a la hora de configurar las diversas mayorías parlamentarias.

La respuesta en contra la realiza el Diputado Alzaga Villaamil (GP de $\mathrm{UCD})^{59}$, en el sentido de que "en la medida en que es una materia tan opinable y en que no bay un consenso doctrinal al respecto, se plantea la gran cuestión de si debe ser o no objeto de constitucionalidad», ya que la Constitución debe ser breve. Hace un interesante repaso teórico, de historia constitucional y de derecho comparado, y defiende que "La representación política ha de atender también a una serie de condicionantes sociales y a la necesidad de lograr mayorias sólidas de gobierno, y aún más, a la imperiosa necesidad de consolidar la democracia».

El Diputado Fajardo Spínola (GP Socialistas del Congreso) defiende también la referencia a la proporcionalidad, aunque con disposición a su exclusión si se aprueba la referencia a la población o al número concreto de escaños del

59 Íbid, pp. 2834 y ss. 
Congreso. Destaca, al inicio de su intervención, el doble sentido de la proporcionalidad referido al comienzo, "veo también, por las intervenciones babidas, que se trata de confundir, si es que no se está confundido, en la diferencia que existe entre un sistema electoral proporcional y el criterio de la distribución proporcional del número de escaños, proporcionalmente a la población» ${ }^{60}$. El Diputado Pérez-Llorca Rodrigo (GP de UCD) realiza una aclaración al respecto que resulta reveladora de cara a las conclusiones finales. Afirma el Diputado que «Ha habido, en un persistente intento de constitucionalizar los intereses electorales de determinados partidos, la proposición de que consagráramos en esta Constitución un sistema de representación proporcional con correctores territoriales, un sistema como el vigente que es evidente favorece a los dos grandes partidos. Nosotros boy podriamos haber hecho ese pacto, que bubiera hecho de esta Constitución una Constitución bipartidista, una Constitución para el reparto electoral con fórmulas en las que determinados partidos pretendian, por supuesto, asegurar ventajas adicionales» ${ }^{61}$. Su defensa se basa en que a pesar de ello, su Grupo ha preferido no constitucionalizar la cuestión. Por una parte, esta afirmación deja claro uno de los inconvenientes que siempre se le han achacado al sistema electoral, el de su tendencia bipartidista. Por otra parte, y teniendo en cuenta que finalmente sí se acordaría por parte de los grupos la introducción de la proporcionalidad en el texto, podemos entender este posicionamiento como parte de esa apariencia de acuerdo y, por tanto, de aceptación del sistema electoral por parte de todos los grupos a que hemos hecho referencia con la redacción del RDLNE, en lo que se ha entendido como una manipulación del grupo predominante ${ }^{62}$.

El Diputado Solé Tura (GP Comunista) ${ }^{63}$ en su defensa de la introducción del criterio proporcional en la redacción del artículo afirma que si no se quiere que este criterio conste es porque se piensa que el mismo debe ser mayoritario. Así, "Este creo que es un tema clave y que nos exime de tener que ir a muchos refinamientos técnicos en este momento, porque es un problema politico y la cuestión es si vamos a ir o no a un sistema mayoritario, es decir, si vamos a ir o no a un sistema en que el país se divida en dos bloques antagónicos (...) tiene que adoptarse un criterio, directo, de cuál tiene que ser nuestra legislación electoral y en este criterio directivo no puede dejarse a que futuras mayorías puedan consolidar su mayoría en función de intereses partidistas».

Se darán otras defensas de enmiendas en este sentido, referidas a la incorporación de la proporcionalidad en la redacción o, al menos, la concreción del número de escaños presentes en la Cámara o los criterios de asignación territorial y por población ${ }^{64}$. Incluso en el debate del día 20 de junio, en el que se presenta

60 Íbid, p. 2837.

61 Íbid, p. 2839.

62 Lago, I. y Montero, J.R., Ob. Cit., p. 284.

63 Íbid, pp. 2839 y 2840.

64 Así las defensas de los Diputados Roca Junyent (GP de la Minoría Catalana), p. 2843; Vizcaya Retana (GP del PNV), p. 2849; Martín Toval (GP Socialistes de Catalunya), p. 2853; y Solé Tura (GP Comunista), p. 2855. 
la enmienda consensuada que dará lugar al acuerdo definitivo de la Comisión, el Diputado Solé Tura (GP Comunista) presentará una enmienda in voce, sobre la presentada por el GP Socialistas del Congreso en este sentido ${ }^{65}$. Esta enmienda recoge de nuevo la elección de un escaño por cada 75.000 habitantes o fracción superior a 40.000, «teniendo en cuenta además que, según el texto de la enmienda «in voce» presentada, se asegura una representación por provincia y luego se establece que el resto de Diputados se repartirá con arreglo a la distribución proporcional, nos podemos encontrar con que la regulación que aqui hagamos, si se mantiene el minimo de 300, tenga un componente más mayoritario que el que ha tenido el actual Congreso. Es decir, todos sabemos que en circunscripciones pequeñas en número, el elemento proporcional juega relativamente poco, y entonces podemos estar proclamando el principio de la proporcionalidad, pero al mismo tiempo reduciendo de tal manera el número de Diputados que en la práctica hagamos que en gran parte el criterio que rija en las circunscripciones sea el mayoritario». Es destacable esta intervención por cuanto, efectivamente, este es uno de los principales problemas del sistema electoral actual ${ }^{66} \mathrm{y}$ que ya se ha comentado también anteriormente. Sabemos, con base en los resultados electorales de estos años, que el efecto de las circunscripciones pequeñas aporta un claro sesgo mayoritario al sistema electoral, ya que en este caso la proporcionalidad prácticamente no tiene relevancia.

Para finalizar con las intervenciones referidas al art. 63 que tuvieron lugar en la Comisión, destacaremos también la realizada por el Diputado Letamendia Belzunce (GP Mixto) ${ }^{67}$, en tanto que incorpora novedades al debate que resultan muy interesantes desde la perspectiva actual en el sentido de nombrar a movimientos y colectivos invisibles en el momento histórico de los debates. Este Diputado critica la ausencia de proporcionalidad del sistema electoral del momento - y mediante el cual se configuró la Cámara- y por haber dejado fuera a pequeños partidos y a otras voces, «voces revolucionarias que encarnan utopías de construcción de sociedades futuras, pero utopías necesarias para que este mismo cambio de progreso pueda un día producirse; voces que reflejan reivindicaciones de sectores marginales, como el de las asociaciones feministas, como el de los movimientos ecologistas, como el de las minorias sexuales castigadas y sometidas a la Ley de Peligrosidad Social. Y me estoy refiriendo, igual me da que la prensa me haga objeto de chistes o que las derechas se rasguen las vestiduras, a los homosexuales y prostitutas». Critica, además, la aplicación de la fórmula D’Hondt como generadora de desproporcionalidad del sistema. Esta intervención, vista en la perspectiva del tiempo, es muy clarificadora. De hecho, la introducción de criterios de representación proporcional por sexo en las listas electorales realizada en 2007 obedece, precisamente, a la falta

65 Diario de Sesiones $n^{\circ} 93$, de 20 de junio de 1978, p. 3522. La enmienda será votada previamente a la definitiva, rechazándose por 18 votos en contra y 15 votos a favor.

66 Penadés, A. y Santiuste, S., Ob. Cit., p. 97; Guillén López, E., Ob. Cit., p. 208.

67 Diario de Sesiones $n^{\circ} 78$, de 1 de junio de 1978, p. 2848. 
de representatividad de parte de la población, las mujeres ${ }^{68}$. Esto también se debe a la importancia fundamental que tienen los partidos políticos en la configuración de las listas electorales y a cómo la presencia de unas personas u otras en esas listas no siempre obedece a criterios de funcionalidad o representatividad de colectivos, sino que habitualmente se debe a decisiones internas de los propios partidos basadas en intereses internos.

\section{C) Debates sobre el art. 64: el Senado}

Hay que destacar que el debate en torno a este artículo resultaría menos intenso, debido a que la defensa de las enmiendas se realizaría el último día de sesiones de la Comisión, cuando ya existía una redacción más o menos consensuada, aunque en una negociación paralela, como ya se ha explicado.

Salvo la intervención del Diputado Vizcaya Retana (GP del PNV), criticando que se vuelva a representar por provincias, y del Diputado Gastón Sanz (GP Mixto), defendiendo mantener el texto de la ponencia, las intervenciones más destacables serían las del GP Comunista que, recordemos, no había consensuado la redacción definitiva propuesta.

El debate se inicia así con la intervención del Diputado Solé Tura (GP Comunista ${ }^{69}$ con la defensa del Voto Particular presentado en el Informe de la Ponencia. De esta intervención, destaca la afirmación de que «el Senado sólo tiene sentido como Cámara representativa de las autonomías, esto es, como Cámara representativa de las nacionalidades y regiones. Si no es así, el Senado carece propiamente de sentido, porque una segunda Cámara que sea una Cámara de duplicación de las labores de la Cámara Baja, del Congreso de los Diputados, es pura y simplemente una pérdida de tiempo en el terreno legislativo». Si bien es cierto que a lo largo de los debates se observa una aceptación generalizada del bicameralismo ${ }^{70}$, esta afirmación en el debate de la Comisión, aporta una pequeña perspectiva diversa, aunque sólo referida a que la segunda Cámara no ejerza efectivamente la representación territorial.

La respuesta contraria se realizaría por parte del Diputado Alzaga Villaamil (GP de UCD) ${ }^{71}$, argumentando que «la bistoria política y constitucional de los países más avanzados en su régimen de convivencia acreditan que, en importantes ocasiones, una

68 Por ejemplo, un acercamiento a la cuestión puede verse en SEvilla Merino, J., (2010): «De la política de cuotas al derecho de la igualdad en la representación: especial referencia a Les Corts Valencianes», Corts: Anuario de derecho parlamentario, n 24, 2010, pp. 279-314; y en GómEz FERNÁNDEZ, I., «Democracia paritaria y paridad electoral: conceptos básicos para alumnos de primero», en PALACios RomeO, F.J. y Cebrián Zazurca, E., Elegir cómo elegir: retos y urgencias del régimen electoral en España, Fundación Manuel Giménez Abad, Zaragoza, 2018, pp. 161-206.

69 Diario de Sesiones $n^{\circ} 93$, de 20 de junio de 1978, pp. 3524 y ss.

70 Elizalde Pérez, J., «Artículo 69. El Senado», en Alzaga Villaamil, O., Comentarios a las Leyes Políticas. Constitución Española de 1978, Tomo IV, Editoriales de Derecho Reunidas, Madrid, 1989, p. 161.

71 Diario de Sesiones $n^{\circ} 93$, de 20 de junio de 1978, pp. 3525 y ss. 
segunda Cámara es un contrapeso eficaz de la Cámara Baja y entendemos también que permite una reconsideración de las tareas legislativas». De esta afirmación se extrae la defensa de la existencia de la segunda Cámara a pesar de que esta no ostente la representación territorial, siendo por tanto una Cámara con un papel moderador.

Por otra parte, al defender el Diputado Alzaga la enmienda in voce consensuada y que sería votada favorablemente — a la que nos hemos referido anteriormente-, el Diputado Solé Tura (GP Comunista) ${ }^{72}$ respondería destacando el sentido conservador de la enmienda, y que tendrá como consecuencia "un Senado que va a tener los exactos defectos que pueda tener el actual (...) y, en definitiva, el establecimiento de un correctivo de representación mayoritaria», añadiendo que «Se podría entender, en todo caso, que esto del contrapeso es una realidad si el artículo que bemos aprobado anteriormente, el artículo 63, tuviese un carácter de representación proporcional realmente estricto. Pero es que tampoco es así, pues también hay correctivos tanto por la escasez del número de los congresistas que vamos a elegir como por asegurar que cada provincia tendrá un número mínimo, etc.».

Con estas intervenciones se destaca el hecho de pronosticar que, con la forma de elección de los escaños al Senado, ya se preveía que esta Cámara no tendría ninguna función de representación territorial y que aportaba un sesgo aún más mayoritario al sistema electoral en general de las Cortes Generales.

\section{Debates en el Pleno del Congreso de los Diputados}

Los debates en el Pleno del Congreso de los Diputados se desarrollaron entre los días 4 y 21 de julio de 1978. El primero de los días se produce el debate general, refiriéndose a la cuestión que nos ocupa dos de las intervenciones. Por una parte, el Diputado Carrillo (GP Comunista) se refiere al sistema electoral al Congreso de los Diputados, criticando la subrepresentación de las zonas más pobladas en favor de las zonas rurales deshabitadas y los efectos mayoritarios de la fórmula D'Hondt ${ }^{73}$, aunque la fórmula electoral no viniera expresamente recogida en el texto constitucional. Por otra parte, el Diputado Fraga (GP de AP) defiende de nuevo que el sistema electoral se recoja en la ley y se posiciona en favor del modelo mayoritario ${ }^{74}$.

Los debates sobre el articulado se produjeron en la sesión de 12 de julio de 1978. Respecto del art. 63 fueron dos las enmiendas presentadas y defendidas: la del GP de AP para mantener el texto de la Ponencia, y la del GP Comunista para defender la última enmienda in voce presentada en la Comisión de cara a aumentar el número de escaños de la Cámara.

72 Íbid, pp. 3528 y ss.

73 Diario de Sesiones del Congreso de los Diputados, Sesión plenaria nº 32, 4 de julio de 1978, p. 3784. Disponible en http://www.congreso.es/public_oficiales/L0/CONG/DS/C_1978_103.PDF (última consulta 15/11/2019).

74 Íbid, pp. 3779 y 3780. 
La defensa que realiza el Diputado Fraga Iribarne (GP de AP) $)^{75}$, como ya se ha expuesto, se basa en el mantenimiento del texto de la ponencia. De esta intervención, similar a la realizada en el seno de la Comisión en lo que respecta a la doctrina de la representación, podríamos destacar que «El sistema de representación proporcional, en mi opinión, no es un buen sistema, porque tiene que realizarse por listas. Si son de base provincial puede haber listas, como ba ocurrido en Madrid y Barcelona, que se acercan a la cuarentena de miembros», este hecho, le lleva a concluir que «Evidentemente, un sistema en el cual los representantes no son designados por los representados, ni siquiera conocidos por ellos, en los que éstos delegan totalmente en los Partidos su selección y, concretamente, hay que decirlo, en la maquinaria de los Partidos». Esta afirmación, permite observar otra de las críticas habituales que se realiza al sistema electoral, por cuanto las decisiones en torno a la composición de las listas dependen de los partidos, lo que desvirtúa la prohibición del mandato imperativo a través de la denominada «disciplina de partidos». Relacionado con esto también, la importancia de la decisión de los partidos políticos de quiénes van a ostentar finalmente puestos de representación.

La respuesta contraria la realizaría el Diputado Alzaga Villaamil (GP de $\mathrm{UCD})^{76}$. De esta intervención se destacaría la argumentación en torno al cambio de posición del GP de UCD, de lo defendido y acordado en la Ponencia y en la primera parte del debate en la Comisión, y el resultado final con el texto acordado. Este cambio se produjo debido a que «Esa desconstitucionalización permitía poner en grave duda si la alternativa ofrecida al elector iba a ser verdaderamente pluralista», por lo que «UCD pensó, desde la responsabilidad, que esas dudas no podían quedar sin despejarse en estas Constituyentes». Además, recuerda que el sistema electoral mayoritario históricamente en España ha dado lugar a un constante fraude electoral. Defiende que el sistema proporcional no es incompatible con la formación de gobiernos sólidos y que, además, impide este tipo de fraude caciquil.

El Diputado Solé Tura (GP Comunista) ${ }^{77}$, defenderá la enmienda presentada de cara a aumentar el número mínimo de escaños establecido por el artículo a 350, ya que con la configuración actual, "No es posible dar a las provincias más pobladas esa proporcionalidad que les correspondería, porque se sobrepasaría el tope máximo que acabamos de asignar», dando lugar a «una extrema desproporcionalidad a la hora de la representación».

Ambas enmiendas defendidas serían rechazadas en la votación ${ }^{78}$, por lo que el texto del art. 63 se mantendría tal y como había sido acordado por la Comisión.

75 Diario de Sesiones del Congreso de los Diputados, Sesión plenaria nº 37, 12 de julio de 1978, pp. 4177 y ss. Disponible en http://www.congreso.es/public_oficiales/L0/CONG/DS/C_1978_108.PDF (última consulta 15/11/2019).

76 Íbid, pp. 4180 y ss.

77 Íbid, pp. 4184 y ss.

78 La enmienda del GP de AP sería rechazada por 21 votos a favor, 251 en contra y 2 abstenciones; por su parte, la enmienda del GP Comunista sería rechazada por 115 votos a favor, 146 en contra y 7 abstenciones. 
Respecto del art. 64, las enmiendas defendidas en el Pleno serían las del GP Comunista, en el sentido de defender la representación territorial del Senado a través de las Comunidades Autónomas. El Diputado Vizcaya Retana (GP del PNV) ${ }^{79}$ acumulará la enmienda presentada a la defendida por el GP Comunista, además de retomar la idea que ya habíamos visto de inutilidad de un Senado no territorial, "Por eso el Grupo Nacionalista Vasco plantea esta alternativa en su enmienda: o existe como Cámara de las comunidades autónomas o provincias que todavía no han accedido a esa categoría y cuya presencia se puede regular a través de una disposición transitoria como la del texto de 5 de enero, o hay que reconocer la total inutilidad de esta segunda Cámara». Finalmente, el Diputado Gastón Sanz (GP Mixto), defenderá de nuevo el texto presentado el 5 de enero, más teniendo en cuenta que, gracias a las preautonomías, ya existe un mapa autonómico o está a punto de definirse.

En este caso, también las enmiendas presentadas serán rechazadas por la votación, por lo que el texto final será el mismo que el establecido por la Comisión.

\section{LOS DEBATES CONSTITUCIONALES EN EL SENADO}

El sistema electoral a las Cortes Generales —especialmente en el referido al Senado- sufrió diversas modificaciones a su paso por el Senado.

En el Senado se presentaron 1.128 enmiendas al texto constitucional remitido por el Congreso ${ }^{80}$. De ellas, 20 enmiendas se dirigirían al art. 63, y 65 enmiendas al artículo 64.

\section{Modificaciones del Senado a la composición y sistema electoral del Congreso de los Diputados}

Las enmiendas presentadas al art. 63, podrían agruparse en los siguientes grandes grupos: aquellas orientadas a la determinación de los escaños por cuota de población ${ }^{81}$; las que defienden que el sistema se decida por la ley electoral posterior $^{82}$; enmiendas referidas al aumento del número de escaños del Congreso ${ }^{83}$; las que suponen la inclusión de las islas en la asignación de escaños ${ }^{84}$; las que proponen incluir expresamente a Ceuta y Melilla en la redacción ${ }^{85}$.

79 Íbid, p. 4192.

80 Documento disponible en http://www.congreso.es/constitucion/ficheros/enmiendas/enmsenado. pdf (última consulta 15/11/2019).

81 Así, las presentadas por los Senadores Mateo Navarro (Progresistas y Socialistas Independientes) y la del propio Grupo.

82 La presentada por el Senador Cacharro Pardo (Mixto).

83 Presentada por Entesa dels Catalans.

84 Enmiendas presentadas por los Senadores Cabrera Cabrera (Progresistas y Socialistas Independientes), Matutes Juan (Mixto), Padrón Padrón (UCD) y Galván González (UCD).

85 Enmiendas presentadas por Matutes Juan (Mixto) y por el Grupo de UCD. 
Cabe destacar que la Ponencia se reunió entre los días 8 y 17 de agosto de 1978 , pero finalmente no elaboró su Informe. Por ello, los debates se desarrollaron directamente en la Comisión que se reunió entre el 18 de agosto y el 14 de septiembre de 1978. Es llamativo que los debates referidos a estos artículos también fueron pospuestos del orden natural de los debates que tuvieron lugar respecto del articulado: debían haberse debatido en la Sesión n $n^{\circ} 9$ de 31 de agosto, se pospusieron a la Sesión $n^{\circ} 10$ de 1 de septiembre y finalmente fueron debatidos en la sesión $\mathrm{n}^{0} 11$, de 5 de septiembre ${ }^{86}$. Tras las defensas y las votaciones, la única enmienda de contenido aprobada fue la presentada por UCD — referida a Ceuta y Melilla-, por unanimidad.

Con todo ello, queda redactado el texto final del ahora artículo $67^{87}$ recogido en el Dictamen de la Comisión del Senado ${ }^{88}$.

El debate sobre este nuevo artículo 67 en el Pleno del Senado tuvo lugar el 29 de septiembre de $1978^{89}$, aunque no se aprobó ninguna de las enmiendas defendidas, por lo que no se introdujeron modificaciones al texto surgido de la Comisión.

\section{Modificaciones del Senado a la composición y sistema electoral del Senado}

El grueso de las enmiendas presentadas en el Senado sobre el sistema de elección y composición lo fueron, precisamente, referidas al Senado. Las mismas pueden ser agrupadas en torno a las siguientes cuestiones: que los escaños al Senado

86 Los debates se encuentran recogidos en Diario de Sesiones del Senado, Comisión de Constitución, Sesión $\mathrm{n}^{\circ} 11,5$ de septiembre de 1978, disponible en http://www.congreso.es/public_oficiales/L0/SEN/ DS/S_1978_049.PDF (última consulta 15/11/2019).

87 Art. 67 del Dictamen de la Comisión del Senado:

«1. El Congreso se compone de un mínimo de 300 y un máximo de 400 Diputados, elegidos por sufragio universal, libre, igual, directo y secreto, en los términos que establezca la ley.

2. La circunscripción electoral es la provincia. Las poblaciones de Ceuta y Melilla estarán representadas cada una de ellas por un Diputado.

La ley distribuirá el número total de Diputados, asignando una representación mínima inicial a cada circunscripción y distribuyendo los demás en proporción a la población.

3. La elección se verificará en cada circunscripción atendiendo a criterios de representación proporcional.

4. El Congreso es elegido por cuatro años. El mandato de los Diputados termina cuatro años después de su elección o el día de la disolución de la Cámara.

5. Son electores y elegibles todos los españoles mayores de edad que reúnan las condiciones fijadas por la ley electoral. La ley reconocerá y el Estado facilitará el ejercicio del derecho de sufragio a los españoles que se encuentren fuera del territorio de España.

6. Las elecciones tendrán lugar entre los treinta y los sesenta días posteriores a la terminación del mandato de la Cámara. El Congreso electo deberá ser convocado dentro de los veinticinco días siguientes a la celebración de las elecciones."

88 Boletín Oficial de las Cortes, $\mathrm{n}^{\circ}$ 157, de 6 de octubre de 1978, disponible en http://www.congreso. es/public_oficiales/L0/CONG/BOCG/BOC_157.PDF (última consulta 15/11/2019).

89 Debates disponibles en Diario de Sesiones del Senado, Sesión plenaria n 36, 29 de septiembre de 1978, disponible en http://www.congreso.es/public_oficiales/L0/SEN/DS/S_1978_062.PDF (última consulta 15/11/2019). 
sean decididos por las Comunidades Autónomas ${ }^{90}$; que la circunscripción electoral sea la Comunidad Autónoma ${ }^{91}$; inclusión de las Islas ${ }^{92}$; incorporación de Ceuta y Melilla ${ }^{93}$; aquellas orientadas a la existencia de escaños en el Senado designados por el Rey ${ }^{94}$; que se incorporen las provincias con entidad regional histórica y de régimen especial como Comunidades Autónomas ${ }^{95}$; eliminar la distinción entre Comunidades Autónomas uniprovinciales y el resto de Comunidades en cuanto a la asignación de escaños ${ }^{96}$.

Durante los debates en la Comisión, destaca la enmienda in voce presentada por el Senador Satrústegui Fernández (Progresistas y Socialistas Independientes $)^{97}$, que incorporaría la referencia inicial sobre que «El Senado es la Cámara de representación proporcional». Por su parte, el Senador Jiménez Blanco (UCD) ${ }^{98}$ presentaría otra enmienda in voce que daría la redacción definitiva a la composición de la Cámara, completada por otra enmienda in voce planteada por el Senador Fernández-Torrecilla (Socialista) ${ }^{99}$.

Así, quedará cerrada la redacción final del ahora art. $68^{100}$ recogida en el Dictamen de la Comisión del Senado.

El debate sobre este nuevo artículo 68 en el Pleno del Senado tuvo lugar el 29 de septiembre de $1978^{101}$, aunque en este caso tampoco se aprobó ninguna de las enmiendas defendidas.

90 Enmiendas de Mateo Navarro (Progresistas y Socialistas Independientes), Entesa dels Catalans y Satrústegui Fernández (Progresistas y Socialistas Independientes).

91 Enmienda del Grupo Progresistas y Socialistas Independientes.

92 Enmiendas presentadas por Cabrera Cabrera (Progresistas y Socialistas Independientes), Padrón Padrón (UCD), Galván González (UCD), Pérez-Maura (UCD), Cambreleng Roca (UCD) y Olives Pons (UCD).

93 Enmienda del Grupo UCD y Lería y Ortiz (UCD).

94 Enmienda del Grupo de UCD, Sánchez Agesta (Independiente), Iglesias Corral (Mixto), Primo de Rivera y Urquijo (Independiente), Zaragoza Burillo (Mixto) y Grupo Agrupación Independiente.

95 Enmienda presentada por Sarasa Miquélez (UCD).

96 Enmienda presentada por de la Cierva y de Hoces (UCD).

97 Diario de Sesiones del Senado, Comisión de Constitución, Sesión n 11, 5 de septiembre de 1978, p. 2239

98 Íbid, pp. 2249 y ss.

99 Íbid, p. 2251.

100 Art. 68 del Dictamen de la Comisión del Senado:

«1. El Senado es la Cámara de representación territorial.

2. En cada provincia se elegirán cuatro Senadores por sufragio universal, libre, igual, directo y secreto por los votantes de cada una de ellas, en los términos que señale una ley orgánica.

3. Por excepción, en las provincias insulares, cada isla o agrupación de ellas con Cabildo o Consejo insular constituirá una circunscripción, a efectos de elección de Senadores, correspondiendo tres a cada una de las islas mayores — Gran Canaria, Mallorca y Tenerife - y uno a cada una de las siguientes islas o agrupaciones: Ibiza-Formentera., Menorca, Fuerteventura, Gomera, Hierro, Lanzarote y la Palma.

4. Las poblaciones de Ceuta y Melilla elegirán cada una de ellas dos Senadores.

5. Las Comunidades Autónomas que se constituyan designarán, de acuerdo con lo que señalen sus Estatutos, en el marco de una ley orgánica, un Senador y además los que le correspondan en proporción a la población de su respectivo territorio a razón de uno por cada millón de habitantes.

6. El Senado es elegido por cuatro años.»

101 Diario de Sesiones del Senado, Sesión plenaria n 36, 29 de septiembre de 1978. 


\section{CONCLUSIONES}

Tras este breve repaso al proceso de constitucionalización del sistema electoral al Congreso y al Senado, cabe realizar una serie de apreciaciones.

Por una parte, y en relación con el proceso, la de una dudosa transparencia en el mismo. Sabido es que los trabajos de elaboración de la Constitución se realizaron en los órganos pertinentes y también de manera paralela, fuera de los cauces oficiales, a través de acuerdos entre Grupos que con el tiempo hemos podido conocer a través de los comentarios de sus protagonistas. Esto se ve claramente al analizar los debates, ya que tras la presentación y defensa de las enmiendas, las redacciones definitivas se presentan in voce por los grupos, aparentemente surgidas a iniciativa de estos y que obtienen el apoyo mayoritario del órgano. Esto nos impide conocer el verdadero proceso de redacción, si bien es cierto que las diversas posturas iniciales de cada grupo se observan en las posiciones previas. A pesar de esta crítica al proceso, también es cierto que la solución aparece como necesaria, teniendo en cuenta lo enfrentado de algunas posiciones y en favor del tan trascendente «consenso».

Por otra parte, respecto del contenido, llama la atención cómo los posicionamientos de algunos grupos y las enmiendas que no se aprobaron, ya preveían las problemáticas que traería el sistema electoral finalmente aprobado. Así, a modo de ejemplo, podemos citar varias de estas problemáticas ya previstas en los debates. Por una parte, con referencia a los niveles de proporcionalidad del sistema, ya que el margen de mejora en la proporcionalidad de los resultados todavía es mejorable. Por otra parte, y estrechamente relacionado con lo anterior, sobre la sobrerreprentación de las provincias menos pobladas y los efectos mayoritarios en la elección de escaños en ellas. Este es el elemento fundamental que aporta el denominado sesgo mayoritario a nuestro sistema constitucional. Si a esto le sumamos la tendencia conservadora tradicional de las zonas más despobladas encontramos el otro sesgo, el conservador, tradicionalmente achacado al sistema electoral. Finalmente, otro problema ya previsto en los debates sería la no representación territorial del Senado, a pesar de la redacción definitiva de lo que finalmente sería el art. 69 CE. Sabemos que el Senado español no representa efectivamente a los territorios, lo que lo convierte en un elemento moderador dentro del sistema parlamentario, aunque también con una virtualidad relativa, debido a la configuración de bicameralismo imperfecto. Todo ello ha tenido como consecuencia una considerable desafección ciudadana hacia la institución que, unida a su escasa virtualidad, han planteado su reforma en muchas ocasiones.

El tiempo nos ha permitido observar cómo los miedos planteados por parte de los Grupos resistentes a que el Congreso tuviera un sistema de elección proporcional han sido infundados. Si atendemos a la composición de los Gobiernos estatales desde la aprobación de la Constitución de 1978 hasta el año 2019, vemos cómo los mismos han estado compuestos por un solo partido político, ya que las composiciones del Congreso de los Diputados en cada legislatura así lo han 
permitido $^{102}$. Este turnismo bipartidista ha sido consecuencia, entre otros factores, de un sistema electoral planteado para lograr la citada estabilidad en los gobiernos, gracias a los elementos correctores de la proporcionalidad introducidos, y ha dado lugar a una práctica política institucional poco acostumbrada a los acuerdos entre formaciones ${ }^{103}$. Además, estos resultados han dado lugar a mayorías parlamentarias de centro derecha, lo que confirma el ya citado sesgo conservador del modelo.

Sin embargo, este tradicional panorama parece haber cambiado desde las Elecciones Generales 2015 ${ }^{104}$, tras las que se han venido formando diversos grandes Grupos Parlamentarios, investiduras fallidas a la Presidencia del Gobierno, repeticiones electorales y una moción de censura prosperada. Este nuevo panorama nos hace pensar que estamos asistiendo a un cambio en el sistema de partidos operante en España ${ }^{105}$, lo que necesariamente dará lugar a negociaciones y acuerdos entre formaciones que no habían sido habituales hasta el momento. Todo ello, a pesar de que sea recomendable esperar para hacer esta afirmación de cambio en el sistema de partidos y poder determinar si el cambio se implementa o responde a posicionamientos electorales puntuales ${ }^{106}$. Lo que también nos ha permitido esta nueva tendencia es poder analizar el sistema electoral a partir de sus resultados desde una perspectiva diferente ya que, al contar con varios grupos de tamaño considerable en el Congreso de los Diputados, el análisis de los efectos del sistema electoral en la composición de estos grupos parlamentarios resulta muy interesante.

Estos análisis nos permiten afirmar que se mantiene la tendencia de beneficiar a grandes partidos a pesar de la actual existencia de otros, por lo que podemos seguir afirmando que el sistema electoral produce los efectos apuntados, perjudicando en la asignación de escaños a las formaciones más pequeñas en beneficio de las grandes. Que lograr una mayor proporcionalidad del sistema electoral sea algo

102 Un análisis de los efectos que ha venido produciendo el sistema electoral en CASTELLÀ ANDREU, J.M., «Sistema parlamentario y régimen electoral en España: similitudes y diferencias entre la forma de gobierno en el Estado y las Comunidades Autónomas», Cuestiones Constitucionales: revista mexicana de Derecho Constitucional, $\mathrm{n}^{\circ} 27$, julio-diciembre 2012, pp. 73-103.

103 Hasta ahora, el español he sido uno de los pocos gobiernos de los Estados miembros de la Unión Europea compuesto por una sola formación política y único en el que nunca ha gobernado una coalición. A este respecto, puede consultarse información actualizada recopilada por la Fundación CIDOB, disponible en https://www.cidob.org/biografias_lideres_politicos/organismos/union_europea/cuales_son_los_gobiernos_ de_la_ue_partidos_coaliciones_primeros_ministros (última consulta 2/12/2019).

104 Se puede encontrar un análisis en BLANCO VALDÉs, R.L., «El año que vivimos peligrosamente: del bipartismo imperfecto a la perfecta ingobernabilidad», Revista Española de Derecho Constitucional, $\mathrm{n}^{\circ} 109$, enero-abril 2017, pp. 63-96.

105 Sobre esto, también en SÁNCHEZ MuÑOZ, O., «El fin (momentáneo) del bipartidismo en España: análisis de los resultados electorales de 2015 y 2016», Revista Española de Derecho Constitucional, n ${ }^{\circ} 109,2017$, pp. 237-260.

106 Según la tipología definida en Sartori, G., Partidos y Sistemas de partidos, Alianza Editorial, $2^{a}$ edición, Madrid, 2005, pp. 157 y ss., podríamos hablar del paso de un sistema bipartidista a uno de pluralismo moderado. 
negativo para el sistema político implica retomar de nuevo el eterno debate entre representatividad y gobernabilidad. Si el sistema beneficia a unos grupos frente a otros y representa a una parte de la ciudadanía frente a otra implica que cuenta con considerables márgenes de mejora en lo que a justicia se refiere. Que los grupos políticos van a tener que aprender a negociar y a llegar a acuerdos para que esto permita estabilizar los Gobiernos — como ocurre con total normalidad en otros Estados desde hace muchos años- es otra cuestión que no debe impedir mejorar el sistema electoral actual.

Esta revisión de los efectos que ha venido produciendo el sistema electoral a lo largo de toda su vigencia — previa a la Constitución, incluso_-, nos aporta una perspectiva de especial interés cuando revisamos los debates en torno a su configuración, como hemos venido observando. El sistema electoral se dispuso con base en intereses partidistas y de previsión de resultados electorales, lo que resulta evidente teniendo en cuenta que sus carencias ya fueron puestas de manifiesto a lo largo de su proceso de constitucionalización o, al menos, del proceso de constitucionalización que hemos podido llegar a conocer.

$$
* * *
$$

TitLE: The electoral system to the Parliament through the constitutionalization process

Aвstract: Although we know the current configuration of the electoral system for the Parliament, it has special interest to approach the process of creating it. Therefore, we will focus on the amendments and debates that took place in both Houses of Parliament during the constitutional process in order to understand the final wording and the various existing positions.

This will help us to observe how from the moment of the elaboration of the constitutional text the problems that the electoral system would have in the future could be perceived.

Resumen: Aunque conocemos la configuración actual del sistema electoral de las Cortes Generales, resulta de especial interés realizar un acercamiento al proceso de creación del mismo. Por ello, nos centraremos en las enmiendas y debates que tuvieron lugar en ambas Cámaras durante el proceso de redacción constitucional para así comprender las redacciones definitivas y los diversos posicionamientos existentes.

Esto nos ayudará a observar cómo ya desde el momento de elaboración del texto constitucional se pudieron vislumbrar los problemas que el sistema electoral tendría en el futuro.

KeY WORDS: electoral system, constituent, debates, Congress, Senate

Palabras Clave: sistema electoral, constituyente, debates, Congreso, Senado

FECHA RECEPCIÓN: 05.11.2019

FECHA ACEPTACIÓN: 19.02.2020 